Vol. 8, No. 2, 2007

\title{
Palestinian Refugee Children and Education: Challenges for UNRWA
}

Ronald Sultana

University of Malta

\section{Abstract}

The article considers the quality of education that Palestinian refugee children receive in UNRWA schools in the five areas of operation in which they are to be found, namely the West Bank, Gaza, Jordan, Lebanon and Syria. The challenges that UNRWA and its staff have to face are outlined in the context of the UNESCO definition of what constitutes 'quality education.' In this article the present and emerging challenges for UNRWA in delivering sound education are organised around four inter-related categories, namely 'human resource issues', Tearning issues', 'systems issues', and 'physical infrastructure issues'. The claim is made that despite important achievements, there are important shortfalls and gaps in UNRWA services to Palestinian refugee children, and that UNRWA schools are losing ground increasingly in danger of lagging behind host countries. Reasons for this state of affairs are explored.

Keywords: Palestinian refugee children, UNWRA, quality education, UNESCO,

\section{Introduction}

This article sets out to examine the extent to which Palestinian refugee children are receiving quality education in the schools managed by UNRWA(United Nations Relief and Works Agency for Palestine Refugees) in the five areas in which it operates, namely the West Bank, Gaza, Jordan, Lebanon and Syria. In so doing, it will identify the challenges that UNRWA has to face, provide an account of how such challenges are being addressed, and highlight what still needs to be done. First, however, it is essential to define what is to be understood by 'quality education', as this will frame both the account of what was observed in the field, as well as the analysis and recommendations that follow. It is also important to provide a brief outline of the methodology used in the compilation of this study, in order to put the reader in a better position to evaluate the soundness of the data presented. ${ }^{1}$ 


\section{Defining 'Quality'}

The term 'quality education' is here being used in a very specific manner, signalling in particular a concern that goes beyond the guarantee of access, to include a focus on the entitlement, of every person, to an education that is effectively delivered, and experienced by the learner as meaningful, relevant, useful, and empowering. Such an approach to the theme is intimately connected with UNESCO's stance, which was most forcefully articulated at its 32nd General Conference (29 September - 17 October, 2003) through the Communique of the Ministerial Round Table on Quality Education (UNESCO, 2003). Here, quality education was defined as 'essential for equity, equality and the quality of life', and concern was expressed at the differential access to such a public good both within and across nations. Such a state of affairs is deplorable because quality education, 'in addition to being a right ... is a means to fulfil other rights' (UNESCO, 2003: 1).

Given such a rights-based approach to quality education, the Ministerial Round Table, and UNESCO more generally through its Division for the Promotion of Quality Education, have opted to stress equality of learning outcomes, rather than merely equality in opportunities for learning, for while 'access is critical, [it is] not very meaningful without evidence of learning' (Pigozzi, 2003: 4). Learning outcomes can be vastly improved if the inputs into the whole educational enterprise - including such key elements as curricula, teachers, text books, pedagogical methods and resources, assessment strategies, school management, and so on - are sound. But inputs, while necessary, are insufficient in the quest for a quality education for all. They must be framed within a vision that takes into account the challenge of equipping 'all people, women and men, to be fully participating members of their own communities and also citizens of the world... The challenge is to develop educational systems that balance local, national and global aspirations in the context of our common humanity' (Ministerial Round Table, 2003: 2).

Within the context of such a vision, UNESCO has identified six key dimensions that could help give concrete direction to, and sustain, the quest for quality education that is rights-based (Pigozzi, 2003). Five of these dimensions address the level of the learner. From the latter's point of view, it is more likely that the educational experience is effective and empowering if it: [i] is inclusive of diversity, adapting to meet the whole range of learning needs arising from cognitive, social, gender, and other differences; [ii] acknowledges, and connects with the experiences learners bring with them; [iii] proposes relevant curricula 
that convey the wisdom and learning of past generations, but that also address current and emerging concerns; [iv] attends to the processes of social interaction that frame the pedagogical encounter both within the school, and between the school and the community; [v] takes place in a physical and psycho-social environment that is safe, healthy, and respectful of the dignity of the individual. A sixth dimension informed by a rights-based approach to educational quality speaks to the systems level, stressing the importance of an enabling environment that facilitates effective learning. Here, an appropriate legislative framework is clearly essential to formally guarantee educational rights, as is a mechanism to measure learning outcomes, preferably in relation to the achievements of other countries - problematic as such comparative benchmarking may be. However, equally important is an enlightened, supportive educational leadership and administrative system that is capable of generating sound policies, and of mobilising the school and its partners, as well as the required resources, to implement them.

This article will attempt to establish the extent to which Palestinian refugee children have access to these different dimensions of quality education, given the context they have to live in daily across the five territories in which they are dispersed, and given the resources that the international community have mobilised on their behalf through the United Nations Relief and Works Agency. First, though, it is important to give a sense of the research methodology used to generate the data reported in this study.

\section{Methodology}

The account that is presented here is based on desk research, largely focusing on documents provided by UNRWA and UNESCO, and on qualitative research involving interviews and observations in Jordan (3-6 March 2004), the West Bank (21-24 March), and Lebanon (25-27 March). A visit to Gaza (planned for March 22) could not materialise due to a sudden closure of borders by the Israeli government, and therefore a 45minute telephone interview was carried out with Gaza's field education program officer instead. A visit to Syria could not be envisaged due to time constraints. Documents concerning UNRWA educational activities in all areas were, however, made available, with the most useful being the education program five-year Medium Term Plan (2004) provided by the UNRWA headquarters. In addition, all Field education program officers gave their feedback on earlier drafts of this study. Research projects carried out previously by the author in the region, including one visit to Syria (Sultana, 2001), and two to the West Bank (Sultana 2002a, 2003), facilitated a better grasp of the overall situation. 
Research in the three areas entailed interviews with UNRWA officials, including a brief but highly instructive meeting with the Director of UNRWA affairs in Beirut, and lengthy meetings with the Director of Education and Field education program officers. Visits were paid to UNRWA schools, where interviews were held with the head $(n=5)$, with groups of teachers $(n=54)$ and counsellors $(n=2)$, with students $(n=147$, including representatives from the student council of one school), and in some cases with small groups of parents as well ( $n=6$, including representatives from the parents' council of one school). Several classrooms were also visited $(n=19)$, in order to observe short lesson sequences, and to note the conditions under which teaching and learning were taking place. Additional insights about a variety of aspects linked to the theme of this study were obtained through interviews with the directors of the 'Slow Learner Centres' [sic] in Amman, the Education Science Faculty in the West Bank, and the Siblin Vocational Training Centre in Lebanon. Informal interviews were also held with UNESCO officials in the West Bank, who held overall responsibility for the organisation of my mission.

Most of the interviews with Agency officials consisted of one-to-one meetings lasting an hour, and in the case of some, much more, given that they accompanied me in my visits to schools and shared with me a great deal of their knowledge of the situation. Interviews with heads, with groups of teachers, and with parents also lasted around an hour on average. Discussions with students took place in groups, without the presence of teachers or heads, and lasted from 10 to 45 minutes, depending on the time available, and their lesson schedules. Conversations took place in English whenever this was possible, with the accompanying UNRWA officer translating to and from Arabic when this was necessary. In all cases, a semi-structured interview schedule was used, with questions generated and constantly modified on the basis of incremental knowledge of the situation. An observational grid was used to facilitate attention to as many quality-related aspects of schooling as possible. Notes were taken during the meetings, as the recording of conversations was considered to be culturally and contextually inappropriate.

Three refugee camps - Baqa'a camp in Jordan, Jalazone camp in the West Bank, and Shatila camp in Lebanon - were also visited, in order to obtain a first-hand impression of the conditions that some of the Palestinian refugees have to endure in their day-to-day lives, and especially to get a sense of the conditions that some Palestinian refugee children returned to after school. In all three cases, the visit lasted well over an hour, providing me with a good opportunity to 
informally interview the accompanying camp officer or his representative, as well to visit some shelters and talk with the families there.

Further interviews were held with Ministry of Education officials in Ramallah, and with three educational researchers with whom I had had contact on prior missions to the region, one of whom has written extensively about Palestinian refugees. The research also entailed a debriefing meeting in Jerusalem, chaired by the representative from the Olof Palme International Centre, where initial and emerging insights about the study could be shared with other NGOs working in the education sector in Palestine. The latter's reactions, as well as the feedback provided by the whole team involved in the preparation of the conference to which this study contributes, were most helpful. An idea of the range of site visits, as well as of the number of interviews held, can be obtained from table 1 (see Appendix).

Despite the broad coverage of areas, as well as of issues, the study is basically a 'dipping into' a complex situation, and there is no claim that the research provides us with anything approaching a 'complete' account that does justice to the theme of quality education provision in the UNRWA schools, the many difficulties that have to be faced, and the efforts made by so many educational workers in the most challenging contexts. Neither is there a claim that this study is 'value free'. Indeed, the declared normative standpoint adopted by this work echoes UNESCO's commitment to the right of every human being to live a life marked by freedom and dignity, with access to quality education contributing directly to the enjoyment of fundamental rights. What is done is to raise several issues that are grounded in the realities observed and reported, that were acknowledged as being relevant and important by the key UNRWA and UNESCO stakeholders, and that have strong resonances with the kinds of concerns that are at the heart of quality education as this has been defined earlier.

\section{Background and Achievements}

The conditions under which many Palestinian refugee children experience life and schooling are somewhat removed from the ideals that the international community has expressed, in terms of the right for all to dignified living, and more specifically, given the object of this study, to a quality education as has been defined. That same international community, through the services of UNRWA, has, since 1950, given concrete support to the attainment of such rights by funding the basic education fof over two million refugee children, as well as technical and vocational education and initial and continued teacher training centres and programs. Conditions of existence for the over 4 
million Palestinian refugees vary from Field to Field, with some host countries being better than others in guaranteeing basic citizenship rights and access to the resources, including educational ones, enjoyed by the general population. ${ }^{2}$ There are important differences between camp and non-camp dwelling refugees, as there are between rural and urban camps in the same area (see, inter alia, Refugee Studies Centre, 2001; International Federation for Human Rights, 2003). But such differences, while occasionally important, are ones of degree, as for many individuals and families, and despite the support of the international community and the host countries, the situation remains critical. Given the scope of this study, it is this general context that will be highlighted, with differences between and within areas occasionally referred to when the situation warrants it.

This article's main intention is to identify the shortfalls and gaps in the provision of educational services to Palestinian refugee children, when these services are held up against the quality education framework as described earlier. In so doing, one runs the risk of ignoring, or downplaying, the many achievements of past and current UNRWA work, and of failing to do justice to the efforts, dedication and commitment of so many educational workers, and the support offered throughout the past half century by the host and international communities. The UNRWA education department's annual reports, as well such statistical publications such as Education Programme: Facts and Figures (UNRWA / UNESCO 2002-03) provide us with a sense of the range of services, as well as the many achievements accomplished in favour of the education of the Palestinian refugee child. Suffice it to mention, in this context, and in relation to elements that have a direct relationship to the quality framework discussed earlier, the following successes attained by UNRWA: ${ }^{3}$

UNRWA provides basic education at the elementary (6 years of schooling) and preparatory ( 3 to 4 years of schooling) to close to 500,000 refugee children in 314 elementary and 337 preparatory schools across its areas of operation. ${ }^{4}$ This service is compulsory, free of charge to both sexes, and available to all those who have refugee status and are registered with UNRWA. The elementary cycle is served by 9,325 teachers, headteachers and assistant headteachers, with the corresponding figure for the preparatory cycle being 5,706 . $52 \%$ of the total of UNRWA's budget, and 70\% of UNRWA staff, are allocated to the agency's education program.

The actual enrolment ratio of the age group corresponding to the elementary school cycle, i.e. 6-11 years, is estimated between 95-98\% 
(UNRWA DoE Statistical Yearbook, 2001/02: 4). The corresponding figure for the preparatory cycle (i.e. 12-14 year olds) is estimated to be between $90-95 \%$. Drop-out rates in the preparatory cycle in 2002/03 stand at $2.58 \%$ for boys, and $2.42 \%$ for girls (UNRWA DoE Annual Report, 2002/03).

Gender parity in access to the basic education level in UNRWA schools has been achieved since the 1960s. UNRWA is also credited with opening the first women's training centre in the Middle East in 1962.

Literacy rates of Palestinian refugees are considerably higher than for the Arab world as a whole, and also higher than for non-refugees where UNRWA operates.

In many cases, Palestinian refugee students in UNRWA preparatory schools outperform students in host country schools in end-of-cycle examinations.

In $2001 / 02$, over $60 \%$ of the 14,620 elementary and preparatory teachers, headteachers and assistant head teachers in UNRWA schools were holders of the first and second university degree or in the process of obtaining a university degree, while $99.68 \%$ of the elementary teaching force and $\mathbf{9 7 . 9 3 \%}$ of the preparatory teaching force. were professionally qualified as teachers in the elementary and preparatory cycles (UNRWA DoE Statistical Yearbook, 2001/02: 13). ${ }^{5}$

While headteachers do not receive specialised training leading to a certificate in school management, and they often suffer from an overload of roles, UNRWA has embarked on a revitalisation of educational leadership thanks to the support of a five-year project grant made by the UK's Department for International Development (DFID). The project, which entails both management development and the affirmation of the School as a Focus for Development, and which was launched in 2001, mobilises the school and the community around those features of school life that are known to have an impact on quality, including school development planning, school-based staff development, the improvement of teaching and learning, the enhancement of partnerships between teachers, and between the school and the surrounding community, and school evaluation and quality assurance through a self-review system. This project was the one most frequently mentioned by heads and teachers, and has clearly had an impact on the way educators are conceptualising - and going about - their work. ${ }^{6}$ 
UNRWA schools follow the curricula and textbooks of the host countries, ${ }^{7}$ and their ability to develop learning materials that directly connect with the frameworks of relevance (social, cultural, economic) of the refugee children they cater for is somewhat constrained. UNRWA has nevertheless developed enrichment materials and resources, of which the best integrated, in cross-curricular terms, is the project on Human Rights, Conflict resolution and Tolerance. The project, co-funded by German and US donors, aims to foster an awareness of, and respect for human rights and global values. ${ }^{8}$

UNRWA has also developed initiatives in order to respond to children's needs under an emergency situation, including the use of music therapy to deal with trauma. In particular, the guidance and counselling program for Palestinian children and students in the West Bank deserves to be highlighted (see Annual Report, UNRWA DoE, 202/03: 24).

UNRWA schools have done - and are doing - a great deal under extremely difficult circumstances to provide the knowledge, skills and attitudes to tens of thousands of Palestinian refugees in order for them to become self-dependent adults, contributing productively to the economy, and having the wherewithal to support their families. They have also helped maintain a sense of identity in a displaced and dispersed people, sustaining the search for a just solution to their problem through an appeal to - and an education in - the rights that ought to be shared equally by all. It is important to stress that such achievements have been attained in the face of adversarial and challenging circumstances, in a context marked by social, political and economic volatility, aggravated by recurring serious crises, and decreasing donor investment. It is to that context, and to the challenges for quality education provision that arise from it, that we now turn.

\section{Current and Emerging Challenges for Quality Education}

A strong impression that comes through from both the interviews and observations carried out in the field, and from an analysis of the documents made available by the different UNESCO and UNRWA offices, is that despite a justified pride in the achievements made over the years, the status of quality education in UNRWA schools may well be at risk. There has been a general deterioration in many of those aspects related to sound education provision as identified earlier, such as physical infrastructure, the overall learning environment, curriculum development and coverage, educational processes and outcomes, and so on. Many interviewees, for instance, expressed fears that lack of resources, together with the inability of donor funding to keep pace with the growth of the student population and the expanding needs of 
an education system that needs to evolve to reflect changing times, are gnawing away at the list of achievements in UNRWA schools. The sense that the international community's attention to their cause may not be as sustained as in the past reinforces the demoralisation that is in danger of becoming installed within the educational community, just when such support is most necessary given the continued stalemate in the search for a political resolution to the problem of Palestinian refugees.

While there are several challenges, gaps, and concerns that deserve to be highlighted in relation to the ability of UNRWA to deliver the quality education it is mandated to provide, only a number will be covered in some depth in this article. These were the ones that stood out most sharply in the data collected, and were also the ones that had the strongest resonances with the concerns of the key players in the five different UNRWA Fields. The present and emerging challenges are organised around four main categories, namely: [i] Human resource issues; [ii] Learning issues; [iii] Systems issues; and [iv] Physical infrastructure issues. Each presenting issue is linked to several others: a feature of schooling that appears to be peripheral to the process of teaching and learning-such as the physical environment, for instance - turns out, on closer inspection, to be inextricably linked to curriculum and pedagogy under the prevailing conditions, and may also have implications for gender or social equity practices, for instance. As with any complex activity, in education the different components related to inputs, processes and outputs are so intricately connected to each other that it is difficult to extricate one element from the other, or to claim that one is more important or indispensable than the other. Nevertheless, the issues are as far as possible disentangled for heuristic reasons, and in order to facilitate clear thinking about the challenges that lie ahead for UNRWA, and a strategic positioning of potential donors as they reflect on where they can have most impact in relation to quality education goals.

Each current or emerging set of issues is first contextualised, and then explored in relation to implications the situation has for the provision of quality education, and in terms of the rights-based framework discussed earlier.

\section{[i] Human Resource Issues}

Background: The adage that 'a school is as sound as its teachers', while somewhat one-dimensional, does remind us that quality education is impossible without the presence of a well-qualified cadre of talented and dedicated staff. There is little doubt that UNRWA teachers 
and headteachers have a sense of commitment to their task that, due to the conditions of existence of their pupils, drives them to give beyond the call of duty. Teachers and headteachers in the UNRWA schools visited were generally proud of their achievements, and pointed to the fact that, in many cases, and despite fewer resources, their students did better in examinations when compared to their counterparts in host country schools. Students readily praised their teachers during interviews, especially those who related positively to them, and who used interactive and innovative teaching methods. It nevertheless became obvious during interviews that teachers were relatively unhappy with a number of aspects related to their profession. They had a sense of belonging to an occupational category that was depressed, and when challenged, declared quite determinedly that they would not like to see their own children become teachers. Many looked back to the time when they felt that being employed as a teacher with UNRWA was considered enviable, which was now no longer the case. Such a sense of dissatisfaction was confirmed by a headteacher who, as one of the leaders of the UNRWA Teacher Council, had a good picture of the overall situation in UNRWA schools.

Teachers felt that the external rewards they got from their work did not match the effort they were required to put into their teaching. Most taught between 26 to 29 forty-five minute periods per week, handling classes with an average of between 40 to 45 students. In addition, teachers felt that were not supported sufficiently in their work, either in terms of having access to pedagogical resources, whether ITbased or otherwise, or in terms of additional staff that attended to tasks complementary to teaching. Unlike host country schools, UNRWA schools do not have support staff such as librarians, guidance counsellors, laboratory technicians, or secretaries. Most of these responsibilities have to be fulfilled by teachers themselves, often without any specialised training in relation to the additional duties they have to fulfil over and above an already full timetable. Headteachers too do not benefit from clerical support, and in many cases are not assisted by deputy principals. ${ }^{9}$

Similar issues related to intensification in working lives were raised by supervisors. Due to austerity measures, the ratio of supervisors to staff has had to be increased from 1:80 in 1990/91 to 1:90 in $2002 / 03$, and the range of tasks they have had to cater for has also increased considerably: the 164 school subject supervisors stationed at the five Education Development Centres - one for each area - not only evaluate teachers, but also the whole school, and they are expected to develop curricula, train teachers, carry out research, promote 
the different education projects in schools, prepare final written examination papers for students, as well as the examinations to recruit teachers - leading one to exclaim, with an obvious sense of frustration: 'We have too many melons to carry at the same time!'

Other than the conditions of work they had to work in, educators identified financial difficulties as a key issue in their lives. Most declared that they were not able to make ends meet with the salary they were getting, and many male teachers admitted that they were obliged to engage in part-time work after school hours in order to provide enough money for their families. ${ }^{10}$ Some were even borrowing money. Their sense of disappointment was heightened by their perception of colleagues who were earning more in the private school sector (including waqf schools), or who, as nationals in the host country, were enjoying benefits that were not available to UNRWA staff. ${ }^{11}$

The general sense of demoralisation among teachers was further accentuated, in the case of those in the West Bank and Gaza, by the climate of antagonism arising from the militarised conflict between Israel and Palestine. Some of the teachers in Gaza are reportedly living in tents, after their houses were demolished. Teachers (and students) are subject to constant harassment at checkpoints, and detained by curfews. A simple 10-minute journey to school can turn into an hour-long saga if teachers or students are stopped, or if they are obliged to take detours in order to avoid being stopped by Israeli soldiers. ${ }^{12}$ In the West Bank and Gaza, between September 2002 and March 2003, a total of 59,086 teaching days were lost (UNRWA Annual Report, 2003: 1). Teachers from Gaza encounter great difficulties in participating in professional development courses organised for them outside their area, and often find themselves 'locked into the system, unable to get width and depth of professional experience', as one UNRWA official put it.

Implications for the provision of quality education: The deteriorating conditions of work, in relation to workload, pupil-teacher ratios, and insufficient number of support/ administrative staff are having a deleterious effect on teachers and on their commitment to delivering quality education. Field education programme officers noted that UNRWA schools are losing the attractiveness they once had for prospective teachers, and that UNRWA schools across all five areas are finding it increasingly difficult to fill key vacant posts, and to attract and keep competent teachers. The lowering of the extrinsic rewards for the teaching profession in UNRWA schools is leading to a corresponding decline in the standards of the educational back- 
grounds of students applying to study to become teachers, and of those accepted as teachers. Most of those taking up education studies in universities have reportedly not opted for teaching as a first choice, and tend to be among the weaker students in the higher education sector. While this is not an issue specific to UNRWA schools, it does nevertheless have implications for the provision of quality education.

The problem of mobility in West Bank and Gaza - accentuated by the building of the barrier, which in some instances separates the school from the community it serves - not only badly affects the teachers' morale, but also leads to a lot of time wastage and the loss of thousands of hours of school work. In 2001/2002, only $28 \%$ of schools fulfilled the minimum number of working days. When schools are interrupted in this way, it is difficult for teachers and students to take up where they had left off before. In the attempt to deal with this problem, teachers are increasingly being deployed on the basis of their proximity to schools, rather in relation to the needs of schools for particular teacher profiles. As headteachers noted, this has an impact on their ability to exploit the full benefits afforded by the DFID project.

\section{[ii] Learning Issues}

\section{Background:}

[a] What the learner brings with him or her: While aspects of this issue will be raised in various sections of this study, it is nevertheless important to highlight the fact that learners are people, with a whole range of physical and psychological needs. Children bring with them to the school the tensions, frustrations, problems and difficulties they experience in their everyday lives at home and in their living environments. For many refugee children, the context in which their daily lives are lived includes deprivation, cramped space, hunger, and in many cases, fear. For some more than for others, and particularly for those living in Gaza and the West Bank, the economic situation is most precarious. $62.3 \%$ of households in the Gaza and the West Bank live below the poverty line (Palestinian Central Bureau of Statistics, July-August 2003), with several pupils not having enough food at home. Fear and anxiety due to closures, curfews, checkpoints, and exposure to violence also have a major impact on the state of mind of students. Experiences such as these cannot be shed at the school gate, and necessarily have a major impact on the ability of students to focus on their own educational development. ${ }^{13}$

[b] Learning environments and resources: While the schools do have textbooks, ${ }^{14}$ and in some cases a modicum of resources such as educa- 
tional (often home-made) charts and posters, it is rare to come across the rich learning environments that are associated with the provision of quality education. I am here referring to libraries and learning centres, computer centres, televisions, video recorders and monitors, overhead projectors, photocopiers, and so on. The science laboratories observed during my field visits had one bench where one experiment could be performed, with students looking on. As one teacher noted, if each student spent one minute looking through a microscope, the lesson was already over before it had even started! Learning Resource Centres (54 LRCs to service all UNRWA schools) are run by unspecialized teachers who, as pointed out earlier, already have a full time teaching load: only 6 LRC assistants have been trained to fulfil this role. In other words, and as teachers pointed out in interviews, there are few resources available to facilitate the development of the kind of interactive teaching situations that we associate with more effective learning. Most classrooms visited or observed while walking through the school had desks arranged in traditional rows, with teachers claiming that the kinds of student desks in use made it difficult to organise group work and interactive learning sessions. All in all, one cannot but help agree with the headteacher who exclaimed, in the course of a visit to classrooms: 'we are doing the best we can in the worst of situations'. ${ }^{15}$

[c] Educational developments in host countries: The poverty of the learning environments in which many Palestinian refugee children are taught in is of concern not only in the absolute sense, in terms of measuring up to the quality contexts that all students, the world over, should have a right to, but for other reasons as well. One of the more important refers to the fact that learning environments in UNRWA schools are increasingly failing to match the curricular and pedagogical requirements determined by educational reforms in the host country. In Jordan and the West Bank and Gaza, the Ministries of Education have extended the basic education cycle to Grade 10. UNRWA schools have not been able to follow suit, with a few exceptions. In some cases, host authorities have introduced new subjects in the curriculum - such as music, technology education, and ICTs - or new teaching and learning approaches - often based on discovery learning - which require new competencies such as critical thinking, key for the 21st century. UNRWA schools often do not have the resources to adopt such curricular and pedagogical innovations, leaving their students at a disadvantage as they also are expected to demonstrate mastery of the same knowledge and skills in the end-ofcycle examinations. In all host countries, curricula are emphasising the development of IT skills, but IT equipment is often missing in 
UNRWA schools. ${ }^{16}$ In Lebanon, a new curriculum has been implemented which not only introduces new subjects, such as technology education, but which also gives importance to modern approaches to learning, such as constructivism. Generally speaking, UNRWA schools have neither the physical space nor the resources to build technology workshops, for instance. They also do not have the equipment to ensure that science, for instance, is taught in an interactive and applied manner. The Lebanese curriculum also assumes that Grade 1 students have two years of kindergarten schooling behind them, which is not the case for Palestine refugee children. ${ }^{17}$

[d] Catering for the special learning needs of students: All quality education systems aim to cater for the learning needs of a broad spectrum of students, from the most gifted to the weakest. This requires profiling strategies that enable teachers to work with specially trained support staff, and drawing on specialised learning resources, to develop Education Plans for individuals and/or groups of students. However, crowded classrooms, too many teaching sessions for each teacher per week, and lack of complementary staff leads to a situation where UNRWA schools find it difficult to follow students, and to develop targeted individual and/or group education programs that attend to specific learning needs. There also seems to be a low awareness among educators concerning the special needs area, and no specific preparation is apparently given at the universities during the initial training courses. In UNRWA schools, the range, type and severity of special needs has its own particular specificity, given the indigent backgrounds students come from, the large families they belong to, and the mental, emotional, and sometimes traumatic stress they have to cope with due to the situations they experience in their daily lives. ${ }^{18}$ An estimate provided by the Medium Term Education Development Plan suggests that as many as 90,000 students in UNRWA schools might require special support, with 8,000 of these having severe learning difficulties requiring targeted assistance. ${ }^{19}$ The response by UNRWA to such needs can only be called limited. In some areas, remedial or supplementary education programs are offered to some pupils with special learning needs. Jordan, for instance, has nine 'Slow Learner Centres'; West Bank schools have pullout programs offering remedial education in some subjects; and Gaza has implemented remedial plans for thousands of students whose achievement in Maths, Arabic, and English was affected by the prevailing situation. Across all areas, many schools organize voluntary extra class periods, include curriculum enrichment materials, or make selflearning kits available. However, most of these are ad hoc initiatives, offered when funding is available. Many of these services are under- 
resourced, and even those that have been in place for some time - such as Jordan's centres servicing remedial education in regular schools - are in danger of closing down as initial NGO assistance is drying out.

No special programs are in place to assist students who come from very deprived backgrounds, including the very poor, and orphans - a particularly significant gap given the extent of indigence among Palestinian refugee families. Similarly significant is the lack of sufficient professional support offered to children who experience violence or conflict-related trauma, particularly in West Bank, Gaza, and Lebanon. UNRWA schools report an increase in violence and antisocial behaviour, reflecting the generally deteriorating conditions of refugees. Examples of such anti-social behaviour include physical aggression, use of sharp objects, sexual misconduct, and attacks on community property. Across all areas, only 16 school counsellors have been appointed to cater for the needs of these young people, when at least $\mathbf{4 3}$ are needed. Other related supportive services that help students make educational and occupational choices are also scarce, and as with counselling, it is teachers untrained in this area, who already shoulder a full burden of teaching load, who have to make up for the shortfall in human resources. ${ }^{20}$

\section{Implications for the provision of quality education:}

All the dimensions outlined above have important implications for the ability of UNRWA schools to provide quality education. The Spartan environment marked by resource deprivation tends to reinforce traditional, text-book based, examination-oriented teaching, and does not facilitate modern and more effective pedagogical approaches, including self-directed learning. When schools fail to provide a rich learning environment, the chances for equitable educational outcomes are greatly diminished, as parents with higher incomes will make up for the deficit of the school. Thus, several students whose parents belonged to professional occupational categories reported that they had a computer, and some could even afford to be connected to the internet. These same parents could also develop their own strategies to cope with the fact that UNRWA schools could not offer Grade 10 classes, and either sent their children to private schools or private tuition, or paid for transport to a Ministry of Education school. All these options were not envisageable for the rest of the parents, who could only fulfil the Grade 10 requirement by sending their children to the closest MoE school on foot. In a number of cases, the closest school is quite distant from the camps, and this acts as a deterrent to attendance, particularly as there is often no organised transport for students from and to the camps. This has a gender dimension to it, 
and several cases were reported where parents preferred not to send their daughters to schools, fearing for their safety.

Such processes reinforce the findings of a great number of studies on achievement, which indicate that educational success is closely correlated to parental background. But we are increasingly understanding how, while such background is often decisive, 'school effects' can counterbalance this trend. In other words, schools, when they offer a quality education, can make a difference, and in some cases can, through targeted and appropriate curricular and pedagogical interventions, greatly affect the educational achievement of individuals and of groups of students. ${ }^{21}$ Due to lack of resources, however, UNRWA schools cannot cater for the special needs of either the weaker or the more gifted students. ${ }^{22}$

\section{[iii] Systems Issues}

\section{Background:}

Double shift schools: The refugee student population has risen from 33,000 in 1950 to 500,000 in 2003 . In the ten years between $1992 / 1993$ and 2002/2003, there has been a $25 \%$ increase in the student population (from 392,757 to 490,949 ). In other words, UNRWA has to cater for 98,192 more students, but the number of schools has only increased from 641 to 656 in the same period. UNRWA is therefore obliged to operate around $73 \%$ of its schools on a double shift basis, a problem that an interviewee referred to as 'fossilised', given that it has become so deeply entrenched and difficult, if not impossible, to overcome. ${ }^{23}$ The problem is further exacerbated in some of the areas, where the attempts to build new schools are obstructed. In the West Bank, for instance, Israeli authorities tend to withhold building permits in Area $\mathrm{C}$, while in Lebanon the government imposes building restrictions on UNRWA.

\section{Implications for the provision of quality education:}

Less contact time in schools reduces the opportunities for learning, and insufficient time to cover the set curriculum, let alone to develop the program of studies in such a way that it reflects the increasing demands made by the progress of science, technology, and knowledge more generally. More importantly, UNRWA students find themselves in a situation where they have to follow the host country's curriculum, and to sit for the host country's examinations, but without having the same amount of class time as their counterparts attending host country schools. The Lebanese curriculum, for instance, is based on a 7hour school day, while UNRWA students are expected to master the same curriculum with 4.5 hours of schooling a day. In some areas, and 
as a direct consequence of less formal instruction time, there is a tendency for learning to be exported outside of the school through homework assignments, with pupils from higher income groups going to private tuition, and with some NGOs in camps offering supplementary education after school hours. Several of the students interviewed indicated that this was the case, but it also became obvious that such practices tend to generate and reinforce inequalities, since educational entitlement cannot be guaranteed by the school-based service due to the lack of sufficient time. There is a gender dimension to this dynamic, given that some teachers reported that traditional families invest scarce resources in their male children, rather than their girls. They are also more likely to invest in elder children, with those born later in the typical 7 to 9 offspring Palestinian family losing out compared to their older siblings.

Double shift schooling hinders teachers from creating sound pedagogical environments through the use and display of resources that sustain learning objectives, since their classrooms are used by another teacher with another class in another shift. Many headteachers and teachers also noted that schools which operate two shifts cannot organise extra-curricular activities, which are particularly important in educational systems which are examination oriented, and in contexts where, as in most camps, opportunities for community-based educational activities are limited.

Reduced time at school obliges children to remain confined in the deprived and restrictive environments of the camps for the rest of the day. This was more likely to be so in the case of girls, who are more liable to being kept indoors. Teaching staff and heads of schools expressed concern that the extensive amount of unoccupied time led young male students into mischief. One headteacher in a school in Lebanon greeted me by showing the number of penknives he had taken away from boys in his school, saying "They keep playing the violent videos they see at home in their heads, and act out what they see on TV on the streets with their friends.' In other cases, male students are more easily recruited for political activities that are not necessarily endorsed by their parents, or by the majority of the members of the camp community.

\section{[iv] Physical Infrastructure Issues Background:}

[a] Rented buildings: One of the key aspects of school infrastructure is its appropriateness for the learning activities that are organised 
within it. In all five areas, $19.3 \%$ of UNRWA-provided education takes place in rented schools $(\mathrm{n}=133)$, with Lebanon topping the list $(45.2 \%)$, followed by Jordan (25.8\%), the West Bank (15.8\%), and Syria (9.7\%). UNRWA does not operate in rented school buildings in Gaza. Rented buildings, unlike purpose built schools, tend to have small rooms, which serve the purpose for which they were built - i:e. as bedrooms, or kitchens for instance - but which provide a very confined space for pupils and teachers alike, particularly given the large student to teacher ratio that is common in UNRWA schools (40/45: 1). Not only do children and young people have to live in cramped quarters in their homes, but they also have to re-live that at school. Rented buildings tend not to have recreational space, such as playing fields or courtyards - even when the curriculum includes timetabled physical education sessions. Such deprivation is especially hard for pupils to bear when they make comparisons with other purpose-built schools in the vicinity, which was the case in interviews held in Jordan, for instance. The rented buildings I saw in the course of my fieldwork tended to be badly lit, poorly ventilated, providing little space for any extra curricular activities such as the expressive arts, or for specialised subjects such as science, ICT, and crafts. ${ }^{24}$

[b] Dilapidated buildings and resources: Another aspect of school infrastructure is the state of the building itself, and whether it is a safe, secure haven for children and teachers. Several schools, whether UNRWA owned or rented, are now very old and reflect more traditional approaches to education, and have become dilapidated, particularly those constructed in the 1950s and 1960s. Roofs leak, walls are mouldy, and there are insufficient toilets to cater for the needs of an increasing student population. In some cases, cracks in the buildings were noted, signalling a serious safety hazard, and the need for major repair and reconstruction works. Walls need to be whitewashed, doors and windows to be fixed, broken glass panes replaced, with many premises requiring extensive maintenance. Students (and teachers) often complain of an irregular supply of water and electricity, of feeling too cold in winter, and too hot in summer, of unhygienic latrines. Plans to improve the situation have fallen short of goals, largely due to lack of funding. Thus, for 2002/2003, only 10 of the 19 targeted dilapidated schools were replaced; only 4 of the 10 targeted unsatisfactory rented buildings were substituted; only 32 of the 75 planned specialised rooms were constructed; and only 3 of the 4 new schools were built. Even basic facilities are in need of attention: student desks, for instance, are often old, worn out, and difficult to write on. In many cases, they are broken and uncomfortable, and seat two students at a time and in some cases, three are crammed on two-seaters. ${ }^{25}$ 


\section{Implications for the provision of quality education:}

Much educational research suggests that healthy, safe, and attractive physical environments, besides being an entitlement for every child, must also be considered part of educational quality, in the sense that they are enablers, rather than causes for student learning. Teachers and students will tend to be more motivated to put in more effort in teaching and learning when they feel supported and esteemed by the surrounding they have to work in. Despite the fact that students came from the camps, many noted in interviews that the school, rather than being a haven, shelter or relief from the camp, merely reflected the same conditions of existence.

Restrictive, unsuitable environments have a major impact on teaching and learning in other ways too. Teachers, for instance, noted during interviews that they felt restricted by the small space they have available to them in rented schools. They experience difficulties in organising interactive learning sessions and in using innovative pedagogy including group work, experiential learning, peer tutoring, collaborative learning and so on. Cramped classroom space not only encourages and reinforces the use of traditional, stand-and-deliver approaches to teaching, but it also discourages the use of expressive arts. This is a critical issue, given that art, dance, music, and so on have great potential in helping children manage the difficult conditions of their existence, and in expressing and giving vent to their frustrations and fears. In many of the classrooms visited in rented buildings, teachers could barely move between students' benches, let alone free up space for activities.

\section{The Way Forward}

What are the main conclusions that can be drawn from a presentation of some of the more critical challenges for quality education provision to Palestine refugee children, and what could constitute the way forward, in order to guarantee such provision? It seems clear that, despite all efforts, and despite the numerous achievements and initiatives, UNRWA schools are losing ground, and are lagging - or increasingly in danger of lagging - behind host countries in a number of areas that have earlier in this study been associated with quality education provision. A major cause of such deterioration is the fact that the flow of resources is failing to match the increase in demands, represented both by a growing student population in UNRWA schools, and by curricular and other school-related developments in the education systems of the host countries. In a number of cases, basic quality education provision is increasingly at serious risk, with a number of factors adding up to jeopardise the gains made over the years, 
affecting the confidence to launch new initiatives. Such factors go beyond infrastructural issues such as adequate school buildings and educational support material, to include the ability of UNRWA schools to attract, keep and develop competent and committed teaching staff.

A number of key recommendations flow from the description and analysis of the situation. Certainly, attempts must be made to improve the attractiveness of being employed as a staff member in UNRWA schools. At one level, improvements in remuneration and work conditions of educational personnel could be offered in relation to specific attainment targets, rather than awarded automatically across the board. Given that 95\% of all UNRWA funds go into staff salaries, it may be more realistic to focus on how the intrinsic satisfaction of working in an UNRWA school can be increased. The project 'The School as a Focus for Development' appears to hold great promise in this regard, and in helping attain improved quality education services. It is of serious concern to note, therefore, that lack of continued funding after the initial 5 -year project cycle may jeopardise the sustainability of the program. The multiplier effects linked to this project include: the provision of opportunities for staff to access continued professional development, the mobilisation of educators and the community around targeted goals for school improvement, the reinforcement of the management and leadership skills of headteachers, and the encouragement of research in the factors that have an impact on achievement. The project can also potentially offset the problems posed by the lack of extrinsic satisfaction (in terms of improved wages) by increasing intrinsic satisfaction with teaching (in terms of identifying more closely with the school goals, and efforts to attain such goals).

Resourcing remains a key stumbling block in the quest for quality education provision, particularly when the affordability of education does not merely focus on access, but on providing adequately for the costs of improving quality (see UNRWA, n.d.). UNRWA would do well to consolidate a two-pronged strategy to ensure that its achievements are not only not whittled away, but rather maintained and indeed reinforced.

One aspect of such a strategy would involve renewed and indeed heightened advocacy vis-à-vis the need for the international community to express its solidarity towards the Palestine refugees and their children in more vigorous, concrete ways. This could mobilise international support for targeted projects that require immediate funding, and where input can make a positive difference to the educational opportunities of Palestinian children in UNRWA schools. ${ }^{26}$ 
But a second aspect would require UNRWA to also consider how it can better cater for those in its charge by examining the extent to which its mode of operation is indeed helping it attain the goals it has set itself. The question 'How can we make quality basic education affordable?' (Buckland, 2003) is a challenge for many governments, and there are some important lessons that can be learnt from international experiences in this regard. Among them is the value of strategic alliances that should be struck between all sectors of society to advance basic education, an approach that was strongly underlined in Jomtien, and that involves the mobilisation of 'private' funds for 'public' schools.

In this regard, UNRWA could consider coming up with strategies to generate more community support for its schools. Parents and members of the community could, for instance, contribute labour and other resources in ensuring that the school environment is improved (e.g. whitewashing of walls, cleaning, art on walls, greenery, curtains, and so on). Library holdings can be dramatically improved if each parent contributes one book per year to the school. In some cases this is already happening. In other cases, the poverty and conditions of life many community members have to endure may make this impossible, particularly as investment in schooling increasingly fails to bring the pay offs expected. But the community's resources can nevertheless be better tapped, particularly if the community is brought closer to the school. Most UNRWA schools are inaccessible after formal instruction time is over. In some cases there are good reasons for this, with no resources being available in order to guarantee safety and security on the school premises, or to ensure that premises are used for educational purposes in line with UNRWA policies and mandate. However, given the indigence that most pupils find in their own camp and home environments, the option of operating the school buildings as community learning nodes, where UNRWA and other NGOs could offer enrichment and supplementary education programmes, play facilities, as well as adult learning opportunities should be carefully examined. ${ }^{27}$ In this regard, UNICEF's admonition that 'when efficiency impacts negatively on equity in access to quality learning, then efficiency becomes a rights issue' (Buckland, 2003: 2) rings true.

A related aspect of efficiency in the generation and use of resources addresses UNRWA's relations with host country schools. The logic behind closer integration of the two school systems is evident, given that UNRWA schools are obliged to follow the decisions made by the educational leaders of the host countries. And yet, in most areas, it seems that no sustained and structured efforts are made to regularly include 
UNRWA officials in the decision-making process. ${ }^{28}$ In most cases, these two systems work in parallel rather than as a network, with little in the way of strategic effort being made to create synergies that would not only reduce duplication in service provision and better use of already available physical and human resources, but may also have an impact on quality education in other ways too. The grouping together of students from the same or from similar backgrounds marked by deprivation, tends to generate a school ethos that magnifies and reinforces the characteristics of the rather homogeneous clientele, and can lead to the creation of a ghetto mentality that determines such important aspects of schooling as motivation and aspiration levels. UNRWA teachers also, in most cases, have come through UNRWA schools themselves, and while this has its positive aspects, in other ways UNRWA may be unwittingly reinforcing the stigma of segregation.

Of course, one could argue, that in this as in many other cases, there may be few alternatives available. But it is precisely in increasing the options for the Palestine refugee community and its children, via development cooperation and other means, that the international community can make a difference. Some of the constraints framing this endeavour are structural, embroiled as they are in complex political realities that few of us can hope to fully understand, let alone shape. But in the meantime the fact remains that education is the only hope that many Palestinian refugees still have in their legitimate aspiration to dignified living. It is in sustaining that hope, and in concretely supporting UNRWA in its mission to be of service, that quality education can be guaranteed, and with it the basic rights and freedoms that we all know all should enjoy.

\section{Notes}

1. An earlier version of this article was presented at a UNRWA conference debating the future of humanitarian assistance for Palestine refugees, held in Geneva between 7-8 June 2004. The conference was hosted by the Swiss Agency for Development and Corporation (SDC) on behalf of the Swiss government. This study is based on the thematic report prepared for that conference by the present author. Thanks are due to UNESCO, to the UNRWA Department of Education in Amman, and to UNRWA staff in the offices in the five areas, and in the schools visited, for the information and insights they kindly provided. The views expressed are those of the author, and should not be attributed to any of the individuals or organisations referred to in the article.

2. The registered refugee population as at 31 December 2002 stood as follows: Jordan =1,698,271; Lebanon=389,233; Syria Arab Republic=405,601; Gaza \& West Bank=1,532,589.

3. The focus here is on general basic education.

4. In Lebanon, UNRWA offers secondary-level education in 5 schools (2292 
students in 2002/03), given the restricted access for Palestine refugees to government schools, and the high cost of private schools. This service, started in 1993, does not fall within the direct purview of this article. However, the fact that the pass rates fell dramatically from 82.6\% in 2001/2002 to 64.94\% one year later indicates that the concern about UNRWA's ability to maintain its standards at this level as well.

5. In 1992, the Agency upgraded its initial teacher training program from a 2year to a 4-year program leading to a first university degree, establishing 3 Education Science Faculties (1 in Jordan, 2 in West Bank). Initial, as well as up-grading and in-service teacher training programs are also offered by the UNRWAUNESCO Institute of Education, which has graduated 20,129 professional staff from 1966 to 2002 (UNRWA DoE Annual Report, 2002-03: 2 ). In the course of carrying out the fieldwork, UNRWA officers, as well as school heads noted that the quality of teachers recruited from universities has declined over the years. This was attributed to the open access policies where quantity, rather than the quality of recruits, seemed to matter. Aspects of university education courses criticised included the focus on subject content knowledge at the expense of pedagogy, and the teaching of context that was not always relevant to the curriculum taught in schools. Many also noted that graduates lacked adequate proficiency in English, a particularly serious issue given the introduction of English as a compulsory subject in all UNRWA schools.

6. By January 2004 , a total of 294 workshops had been offered to 28038 staff across all five areas (see Appendix $V$ ).

7. This was agreed to by representatives of Arab host countries, UNRWA and UNESCO in 1953, in order to facilitate the movement of students between UNRWA and government schools, the entrance of UNRWA students to higher levels of education which the Agency does not offer (namely, secondary education) and, consequently to sit for government examinations as first step to pursue their higher education. UNRWA often finds itself obliged to follow and implement decisions that it has not had a say in formulating.

8. The project has received a broadly positive appraisal in a report dated 31 March 2003, submitted to the UNRWA Director of Education by a representative of the Berlin-based Auswärtiges AMT. The point made by the report that schools tend to emphasise the issue of human rights was borne out by the observations carried out during the fieldwork, with the schools visited often portraying murals on the theme. In one school, student graffiti scribbled onto a poster formally listing a bill of rights promoted by the project read: 'The right to return!'

9. A headteacher is allocated an assistant when the school has 21 class-sections or more.

10. In some of the areas (e.g. Jordan), teachers are only allowed to engage in supplementary teaching (such as giving private tuition). In other areas (e.g. Gaza), teachers are reportedly engaged in all sorts of employment, such as driving taxis or keeping shops. This is not at all uncommon in the Middle East and the Mediterranean region (see Sultana, 2002b).

11. These benefits varied from one area to another. UNRWA teachers noted that, in contrast to host country colleagues, they did not enjoy a decrease in the number of periods they were expected to teach with length of service; they had to complete more years of service before having the right to retire; 
their annual salary increment was halted after 21 years of service; they did not have access to interest-free loans and to transportation allowances; they had less opportunities for career progression, and further certification did not move them faster in their career paths; their health insurance schemes were not as attractive; they did not have nurseries for their children in UNRWA schools. In addition, the introduction by UNRWA of new employment categories for teaching staff in 1999, with reduced salaries and terms of appointment, led to a situation where teachers found themselves on different salary scales, creating misgivings.

12. While this situation is unique to the West Bank and Gaza areas, UNRWA teachers in Lebanon also expressed a sense of frustration in their work related to their own particular political circumstances. The Lebanese government has recently decreed that Palestinian refugees may not have access to over 70 types of occupations, irrespective of their credentials. This has had a major impact on motivation levels of Palestinian students in UNRWA schools. As always, teachers are the front line staff who have to deal with the frustrations of young people who see their futures blocked.

13. Despite the fact that there is some evidence that children adapt to situations of 'normal abnormalcy' (Martín-Baro, 1990; Flores, 1999), continued exposure to violence has a major detrimental impact on the children's psychological and social development as well as on their education. During the early stages of the second Intifada, reports showed that in the areas most affected by the conflict, i.e. Salfeet in the north West Bank, north and south Gaza, Hebron and Bethlehem, 75 percent of adults thought that children were experiencing greater emotional problems and behavioural change. Two separate opinion polls found that some 80 percent of parents thought that their children's behaviour changed (Birzeit University Development Studies Program Survey - February 2001; June 2001; MOSA, 2001). The MOSA study also indicated that repeated exposure to the sounds of shelling and shooting was a major cause of psychological problems among children. In Hebron, parents told counsellors that their children manifested a series of problems in reaction to the situation of political violence. Among these were repeated nightmares, bed-wetting, insomnia and irregular or changed sleeping patterns, increased fear of darkness, parental clinging, fear of sleeping alone, inordinate anxiety related to leaving the house, to meeting strangers, to loud noises and to sudden movements. Some children develop phobias, especially of the sources of violence such as tanks, soldiers, helicopters, and settlers. Many children - particularly the younger ones - act out their fears through imitating soldiers, and often project their fears while at play, and when drawing. Other problems that have been reported include stress, anxiety and irritability, accompanied by the appearance of psychosomatic symptoms including headaches, stomach cramps and skin diseases. Children find it increasingly difficult to concentrate and remain focused on a task. Some children also withdraw from friends and family, engage in risk-taking behaviour, rebel, and reject authority, become aggressive or depressed and pay less attention to personal care. Others show high levels of anxiety, fearing the potential loss of parents. Children having less social and recreational activity, and as a result they experience boredom, are more prone to brooding about life, tend to watch more TV and as a result see more of the violence. Increasingly children feel trapped, discour- 
aged, tense, hyperactive, sad about life, angry, and distrustful of authority. While the majority of young people do their best to avoid direct clashes with Israeli troops, others are propelled to risk acts of rebellion because of a complex mix of anger, bitterness, frustration, patriotism, fatalism and excitement. The results can be violent, unpredictable, and tragic.

14. Textbooks are provided free of charge by UNRWA, and are the same as those used in host country schools. Most of the textbooks I leafed through had clear and attractive layouts, with pictures and illustrations in full colour. Students generally claimed that they found their textbooks useful, though it was also pointed out that many of the texts were much the worse for wear, given that they were re-used from year to year. Neither students, nor teachers felt that the fact of using host country textbooks created a distance between learner and text, due to cultural or other differences, though some did note that they missed explicit references to Palestine, and to the Palestinian situation.

15. Many of the resources observed were linked to the Human Rights, Conflict Resolution and Tolerance project, and included attractive posters, worksheets, videotapes, songs, and so on.

16. Computer science has been introduced in the $7^{\text {th }}$ to $9^{\text {th }}$ grade in West Bank and Syria, and $7^{\text {th }}$ to the $10^{\text {th }}$ grade in Jordan in schools that already have computer rooms or computer laboratories. But in UNRWA schools in Jordan, there are only 32 computer labs and 45 more are actually needed. The corresponding figures for the West Bank are 28 labs (42 more are needed); Syria has no labs when 53 are needed. Overall, 273 IT laboratories are required in UNRWA schools in the five areas, but only 73 are available (see UNRWA Medium Term Development Plan, 2004: 6).

17. UNRWA does not usually cater for this level, but since few can afford private crèche facilities, it operates four French language kindergartens, with 189 children currently enrolled.

18. Each Field has its own specific problems, though it would seem that Lebanon, and West Bank and Gaza provide the most challenging contexts for children to grow up in. In the former Field, $60 \%$ live in poverty, and the problem of domestic violence was often referred to by interviewees (see also Khalidi, 2000 for a report on this issue). In Saida, the head of school informed us that of 429 children, 142 were considered to be 'social hardship cases'.

19. In $2002 / 2003$, special education services supported by ad hoc funding reached 850 slow learners, 1,138 pupils identified as in need of remedial support, 11 blind, 81 deaf and 115 handicapped children.

20. Educational and career guidance can further learning goals and attainment, helping students become more focused, motivated and self-directed in their study. Guidance services can also ensure a better fit between individual profiles and the labour market, as well as further social equity goals (see Watts \& Sultana, 2004).

21. The impact of such 'school effects' on achievement have been highlighted by UNESCO's Delors Report (1996), which referred to the success achieved by the Accelerated Schools program in the USA.

22. In the case of the brighter students, UNRWA used to provide university scholarships to those who excelled in secondary school examinations, 
enabling them to pursue their studies at any university in the Middle East. As from 1997, however, even this program has had to be phased out due to lack of sufficient funding.

23. The increase in student numbers also leads to overcrowded schools and classrooms. One of the WB schools visited was built in 1953 for 300 students. Today the student population has gone up to 1150 . The area per student in UNRWA schools ranges from 0.92 to $1.18 \mathrm{~m}^{2}$, which is low compared to UNESCO standards, established at 1.40 to $1.50 \mathrm{~m}^{2}$ per student (UNRWA / UNESCO, 2003: 5).

24. Any structural change to make the building more suitable for teaching requires the permission of the owner. This approval is not always easily obtained, given that owners are often dissatisfied with the rent they obtain from UNRWA, and have made alternative plans for their property which would bring them more income if only they could dislodge UNRWA from their site.

25. Jordan requires 5000 desks to be replaced, for instance, while the West Bank needs 6,500 - but resources from the General Fund have had to be reserved to purchasing additional furniture to cope with increased classroom size of existing schools.

26. Examples of these that have a strong link to the provision of quality education include: the building of new schools and the refurbishment of old ones, in order to reduce double shift schooling and the occupancy rates of classrooms, and to allow for the implementation of extra curricular activities outside school hours; the establishment of Learning Resource Centres; the construction of Computer Workshops/Labs; the funding of Remedial Teaching, the Slow Learners' Project, and of Special Education; the funding of the Psycho-Social Programme; the Support for the establishment of Extra-Curricular Activities programs (e.g. a sport complex); the provision of school transport to ensure continued access to Grade 10; the award of post-secondary scholarships to talented refugee students and teachers; and the continued support to the 'School as a Focus for Development' project.

27. One of the DFID modules in the 'School as a Focus for Development' project in fact promotes the development of school links with the community, and this may indeed be a most promising strategy to address some of the issues raised in this article.

28. There are, of course, examples of good practice. The Syrian Ministry of Education offered train-the-trainers courses to UNRWA school supervisors in the newly-prescribed $6^{\text {th }}$ and $7^{\text {th }}$ grade textbooks, to train Agency teachers in the summer of 2003 (see UNRWA Annual Report, 2003: 55).

\section{References}

Birzeit University Development Studies Programme Survey (February 2001) Public Opinion Poll (3), the Impact of the Israeli-imposed Siege on Palestinian living conditions.

Birzeit University Development Studies Programme Survey (June 2001) Public Opinion Poll (4), the Impact of the Israeli-imposed Siege on Palestinian living conditions.

Buckland, P. (2003) Making quality basic education affordable: what have we learned? A UNICEF report: http://www.unicef.org/girlseducation/costs.pdf 
International Federation for Human Rights (2003) Palestinian refugees: systematic discrimination and complete lack of interest on the part of the international community. FIDH, no. 356/2, March 2003. Paris: FIDH.

Flores, J.E. (1999) Schooling, family, and individual factors mitigating psychological effects of war on children. Current Issues in Comparative Education, Vol.2(1).

Khalidi, A. (2000) Domestic violence among some Palestinian refugee communities in Lebanon: an exploratory study and ideas for further action. Najdeh Association.

Martín-Baró, I. (1990) Guerra y trauma psicosocial del niño salvadoreño. [The salvadoreña child, war psychosocial trauma.'] In Martín-Baró (ed.) Psicologia Social de la Guerra: Trauma y Terapia. [The Social Psychology of War: Trauma and Therapy] San Salvador, El Salvador: UCA Editores.

Ministry of Social Affairs (2001) Psychological effects of Israeli violence on Palestinian children. May.

Pigozzi, M.J. (2003) How you learn and what you learn are both essential for EFA. Educational Innovation and Information, No.114-115, pp.4-5, IBE, UNESCO.

Refugee Studies Centre (2001) Children and adolescents in Palestinian households: living with the effects of prolonged conflict and forced migration: A regional study. Refugee Studies Centre, University of Oxford.

Sultana, R.G. (2001) Syria's global education initiative. In R.G. Sultana (ed.) Challenge and Change in the Euro-Mediterranean Region: Case Studies in Educational Innovation. NY: Peter Lang.

Sultana, R.G. (2002a) An EMIS for Palestine: The education management information system in the West Bank and Gaza Strip. Mediterranean Journal of Educational Studies, 7, 2: 61-92.

Sultana, R.G. (ed.) (2002b) Teacher Education in the Euro-Mediterranean Region. NY: Peter Lang.

Sultana, R.G. (2003) Education Against the Odds... The Distance Remedial Education Project in Hebron. Amman: UNICEF.

Watts, A.G. \& Sultana, RG. (2004) Career guidance policies in 37 countries: contrasts and common themes. International Journal for Educational and Vocational Guidance, 4:1-19.

Swedish Ministry for Foreign Affairs (2003) Seminar on the Situation of Palestinian Children in the occupied Palestinian territories, held in Stockholm 1-3 October (Summary of discussions, mimeo).

UNESCO (1996) Learning: The Treasure Within. Paris: UNESCO.

UNESCO (2003) Communiqué of the Ministerial Round Table on Quality Education, http://portal.unesco.org/en/ ev.php@URL_ID=16438\&URL_DO=DO_TOPIC\&URL_SECTION=201.html

UNRWA (2002) Statistical Yearbook 2001/2002. Amman: UNRWA Department of Education.

UNRWA (2003) Annual Report 2002/2003. Amman: UNRWA Department of Education (mimeo).

UNRWA (n.d.) Chronic under-funding: impact on services. Directorate of Education, Amman (mimeo)

UNRWA (2004) Medium Term Development Plan. Amman: UNRWA Department of Education (mimeo). 
UNRWA / UNESCO (2003) Education Programme Facts \& Figures: 2002/2003. Amman: UNRWA.

UNRWA (2004) Biennial work plan for curriculum and learning resources and teaching workforce, 2204-2005. Amman: UNRWA Department of Education (mimeo).

\section{Appendix}

\begin{tabular}{|l|c|c|c|c|}
\hline & $\begin{array}{c}\text { Schools } \\
\text { visited }\end{array}$ & $\begin{array}{c}\text { Staff } \\
\text { Interviewed }\end{array}$ & $\begin{array}{c}\text { Students } \\
\text { interviewed }\end{array}$ & $\begin{array}{c}\text { Classes } \\
\text { visited } / \\
\text { observed }\end{array}$ \\
\hline Jordan & $\begin{array}{c}4 \\
(\mathrm{~m}=2 ; \mathrm{f}=2)\end{array}$ & $\begin{array}{c}26 \\
(\mathrm{~m}=20 ; \mathrm{f}=6)\end{array}$ & $\begin{array}{c}94 \\
(\mathrm{~m}=30 ; \mathrm{f}=64)\end{array}$ & 9 \\
\hline West Bank & $\begin{array}{c}4 \\
(\mathrm{~m}=1 ; \mathrm{f}=2 ; \\
\text { co-ed. }=1)\end{array}$ & $\begin{array}{c}12 \\
(\mathrm{~m}=8 ; \mathrm{f}=4)\end{array}$ & $\begin{array}{c}25 \\
(\mathrm{~m}=13 ; \mathrm{f}=13)\end{array}$ & 6 \\
\hline Lebanon & $\begin{array}{c}4 \\
(\mathrm{~m}=2 ; \mathrm{f}=2)\end{array}$ & $\begin{array}{c}21 \\
(\mathrm{~m}=5 ; \mathrm{f}=16)\end{array}$ & $\begin{array}{c}28 \\
(\mathrm{~m}=20 ; \mathrm{f}=8)\end{array}$ & 4 \\
\hline Total & 12 & $59^{*}$ & $147^{*}$ & 19 \\
\hline
\end{tabular}

* Interviews were held with groups. Number ranged from 4 to 10 in the case of teachers, and 6 to 25 in the case of students 